\title{
Early surgery determines recovery of motor deficits in lumbar disc herniations-a prospective single-center study
}

\author{
Nikolaus Kögl ${ }^{1}$. Konstantin Brawanski ${ }^{1} \cdot$ Pierre-Pascal Girod ${ }^{1} \cdot$ Ondra Petr $^{1}$ (i) $\cdot$ Claudius Thomé $^{1}$
}

Received: 6 July 2020 / Accepted: 6 October 2020 / Published online: 4 November 2020

(C) The Author(s) 2020

\begin{abstract}
Background Patients with intervertebral disc herniation undergo surgical removal of herniated disc material in cases of persisting symptoms and/or neurologic deficits. While motor deficits often prompt surgery, little is known about the optimal timing of surgery in these cases. The aim of this study was to prospectively evaluate the impact of timing of disc surgery on motor recovery. Does postponing surgical treatment worsen outcome?

Method In total, 120 patients with sciatica and/or sensorimotor deficits due to a lumbar disc herniation were surgically treated at the authors' center within a 3-month period. In 60 patients, motor deficits were present at the time of admission. Motor function was assessed using manual muscle testing and subdivided according to the Medical Research Council (MRC) scale. Patient demographics, neurologic deficits, duration of motor deficits, treatment characteristics, and outcome were assessed. At a minimum follow-up of 1 year, functional recovery and complications were collated. Patients were subdivided into groups according to the severity of the paresis (MRC $\leq 3 / 5$ vs. MRC $4 / 5$ ). Intra-group differences were compared based on the duration of the neurologic deficits.

Results Patients with moderate and severe paresis $(\mathrm{MRC} \leq 3 / 5)$ benefit from treatment within $72 \mathrm{~h}$ as they were shown to have a significantly higher complete recovery rate at 1 -year follow-up $(75 \%$ vs. $0 \% ; p<0.001)$.

Conclusion Immediate surgery should be offered to patients with moderate and severe motor deficits to increase the likelihood of neurologic recovery. This prospective data may have an impact on emergency triage in these patients.
\end{abstract}

Keywords Paresis $\cdot$ Motor deficit $\cdot$ Recovery $\cdot$ Surgical timing $\cdot$ Disc herniation $\cdot$ Discectomy

\section{Introduction}

The most common cause of sciatica is intervertebral disc herniation or spondylosis leading to mechanical nerve affection $[6,15]$. The annual incidence in the general population that experience sciatica ranges from 1 to $5 \%[9,14]$. The initial treatment of sciatica is conservative due to its favorable natural history as symptoms usually decrease or disappear in 60$80 \%$ within 3 months $[3,26]$. In approximately $20 \%$ of cases, patients undergo surgical removal of herniated disc material because of persisting symptoms, which is usually done within 6-26 weeks in western countries as surgery is economically

This article is part of the Topical Collection on Spine degenerative

Ondra Petr

ondra.petr@tirol-kliniken.at; ondra.petr@yahoo.com

1 Department of Neurosurgery, Medical University of Innsbruck, Tyrol, Austria affordable and associated with only minor risks [3]. Improvement in leg pain is achieved much faster for patients in case of early surgery [22]. Nevertheless, short-term benefits of early surgery level out in medium to long-term follow-up compared to conservatively treated patients [11,21-23].

Neurological deficits such as paresis can be seen in up to 30 to $50 \%$ of patients with symptomatic disc herniation [25]. The recovery rate varies widely in the literature with little information on optimal timing as mild motor deficits may remain stable or even recover with conservative management [25]. Cauda equina syndrome represents a surgical emergency and should be treated within $48 \mathrm{~h}$ as postponing treatment may result in rectal and urinary incontinence. Only $40 \%$ of patients treated after this timeline regained the lost bladder function $[1,4]$.

A recently published retrospective study has also indicated superior outcome for early surgery $(<48 \mathrm{~h})$ in patients with moderate and/or severe deficits according to the Medical Research Council (MRC) $\leq 3 / 5$ [20]. The aim of this singlecenter study was therefore to prospectively evaluate the impact of timing of disc surgery on motor recovery. 


\section{Methods}

A multicenter registry study designed to evaluate the need for an annular closure device (ACD) prospectively assessed lumbar disc herniation patients. The authors enriched the respective single-center data set to analyze patients with motor deficits regarding severity and timing of surgery. After obtaining approval by the institutional ethics committee, this study enrolled consecutive patients from September 2015 to December 2015 with a follow-up of at least 1 year. In total, 120 patients with persistent pain and/or neurologic deficit were treated by lumbar microscopic sequestrectomy/discectomy within this period of time. Detailed information including demographics, medical history, surgery details, radiographic data, and neurologic examination were collected and analyzed. The duration of motor deficits and the existence of a cauda equina syndrome were precisely documented as clearly stated by the patients. In case of unknown duration of motor deficits, the patient was not enrolled in this study. Preliminary prospective data of our group had indicated no complete recovery of severe deficits after $72 \mathrm{~h}$, so that this cut-off value was chosen for analysis. In accordance with clinical guidelines, patients were subdivided into groups according to the severity of the paresis (MRC $\leq 3 / 5$ vs. MRC $4 / 5$ ) [20]. A mild motor deficit was defined as MRC grade 4. This is characterized as active movement against gravity and resistance during manual testing. Grade 3 was defined as moderate, whereas grades $0-2$ were recorded as a severe deficit. The degree of sensory and motor impairment was preoperatively assessed using standard methods. To overcome the challenge of distinguishing between paininduced inhibition of motor function and true motor deficit, analgesics were prescribed and the patients' symptoms were reevaluated. The clinical information was obtained by manual testing as this is not inferior to those documented by EMG [24]. Surgery was performed by several surgeons at the authors' center.

At a minimum follow-up of 1-year functional recovery, residual sciatica and complications were assessed. Follow-up visits were scheduled at 6 weeks and 1 year after surgery. Neurologic examination and manual testing were performed by a single surgeon to minimize interobserver variability.

Complications were recorded as intraoperative, postoperative, and overall complications.

\section{Exclusion criteria}

We excluded all patients, who did not sign the informed consent form (ICF). Underage patients $(<18$ years of age) and procedures in the thoracic and cervical spine were also not included in this analysis.

\section{Perioperative data}

The duration of neurologic deficits, the quality of the sensory deficit, and the existence of cauda equina syndrome were evaluated before and after surgery. Any changes were documented over time. Surgical details such as type of discectomy, intraoperative findings, the use of an annular closure device, and prior surgeries were also documented. All intraoperative and perioperative complications were noted. In case of complications, all additional treatments including the need and time point of revision surgery were documented.

Clinical outcomes including neurologic impairment were evaluated statistically.

\section{Statistics}

Endpoints were analyzed as appropriate in dependence on the data distribution at a two-sided 0.05 level of significance. Detailed descriptive statistics were provided for the data collected and 95\% confidence intervals were calculated for all relevant estimates. Measurements concerning the time course of follow-up were analyzed by ANCOVA or generalized model alternatives for categorical or semi-quantitative data. Distributions of numeric variables were given as mean and $( \pm)$ standard deviation. The Mann-Whitney $U$ test was used to asses intergroup differences of continuous measures. Chisquare or Fisher exact tests were used for dichotomous data analysis depending on the number of subjects involved. A $p$ value of less than 0.05 was considered statistically significant. Data is analyzed for normality by the Kolmogorov-Smirnov test. The Wilcoxon signed-rank test was used for paired data and for the analysis of intragroup changes.

All data was pseudonymized as soon as clinically reasonable. Data entry in an electronic database (SPSS Statistics 25; IBM, Armonk, New York, USA) was performed with pseudonymized data stored according to local regulations in a database.

\section{Results}

One hundred and twenty microscopic disc surgeries were performed within 3 months and 119 (99.2\%) were followed up for at least 1 year. The most common level of disc herniation was L4/5 (56 patients; $46.7 \%$ ).

\section{Demographics}

Sixty-four patients were female $(53.3 \%)$ and the mean age was $49.6 \pm 15.6$ years.

Twenty-five patients (20.8\%) were previously treated with at least one prior surgery at the index level (Table 1). Persistent pain 
Table 1 Demographics and patients' characteristics

\begin{tabular}{ll}
\hline Gender & $N$ \\
\hline Female & $64(53.3 \%)$ \\
Male & $56(46.7 \%)$ \\
& Mean \\
Age (years) & $49.6 \pm 15.9(19-84)$ \\
BMI & $26.0 \pm 4.0(18.3-37.4)$ \\
Index Level & $N$ \\
L2/3 & $3(2.5 \%)$ \\
L3/4 & $8(6.7 \%)$ \\
L4/5 & $56(46.7 \%)$ \\
L5/6 & $1(0.8 \%)$ \\
L5/S1 & $46(38.3 \%)$ \\
L1/2 + L2/3 & $1(0.8 \%)$ \\
L3/4 + L4/L5 & $2(1.7 \%)$ \\
L3/4 + L5/S1 & $1(0.8 \%)$ \\
L4/5 + L5/S1 & $2(1.7 \%)$ \\
Prior surgery at index level & $N$ \\
Primary herniation & $95(79.2 \%)$ \\
Recurrence & $16(13.3 \%)$ \\
Second reherniation & $8(6.7 \%)$ \\
Multiple surgeries at index level & $1(0.8 \%)$ \\
Total & $120(100 \%)$ \\
\hline
\end{tabular}

and acute exacerbation of the symptoms led to surgery in $48.3 \%$ (58) of the cases. Fifty percent of all patients (60) presented with a motor deficit. Of those, thirty-five patients (58.3\%) presented with a mild motor deficit (MRC 4/5), whereas 25 patients $(41.7 \%)$ suffered from a moderate or severe $(\leq 3 / 5)$ paresis. Twelve patients (10.0\%) suffered from an additional adjacent myotome paresis caused by the simultaneous affection of the traversing and exiting nerve roots. Sensory deficits were documented in 94 cases $(78.3 \%)$. A cauda equina syndrome was diagnosed in six cases $(5.0 \%)$ (Table 2$)$.

\section{Outcome}

Recovery of the initial motor deficit was seen in 25 patients (41.7\%) at regular follow-up after 6 weeks. At 1-year followup examination, $35(58.3 \%)$ of all patients with initial motor deficit regained full strength (Fig. 1). Twenty-five (41.7\%) patients initially presented with a moderate and/or severe motor deficit ( $\leq 3 / 5 \mathrm{MRC})$. Thirteen of those $(52.2 \%)$ were treated later than $72 \mathrm{~h}$ after paresis onset. Notably, none of them $(0.0 \%)$ completely regained full strength of the affected myotome (Fig. 2 ). In contrast to this subgroup, 9 out of 12 patients $(75 \%)$ treated within $72 \mathrm{~h}$ recovered completely $(p<0.001)$ (Table 3$)$. In case of moderate and/or severe motor deficits, the mean duration of paresis prior to surgery varied significantly between patients, who recovered and those who did not regain full strength (mean
Table 2 Sensorimotor deficits

\begin{tabular}{ll}
\hline Motor deficit & $N$ \\
\hline No motor deficit & $60(50.0 \%)$ \\
MRC $>3 / 5$ paresis & $35(29.2 \%)$ \\
MRC $\leq 3 / 5$ motor deficit & $25(20.8 \%)$ \\
Sensory deficit & $N$ \\
No sensory deficit & $26(21.7 \%)$ \\
Paraesthesia & $10(8.3 \%)$ \\
Hypesthesia & $82(68.3 \%)$ \\
Dysesthesia & $2(1.7 \%)$ \\
Cauda equina syndrome & $N$ \\
No vesicorectal disorder & $114(95.0 \%)$ \\
Vesicorectal disorder & $6(5.0 \%)$ \\
\hline
\end{tabular}

$1.9 \pm 0.8$ vs. $15.2 \pm 23.8$ days). Furthermore, none of the patients with an initial deficit grade MRC 0 or 1 recovered completelyindependent on surgical timing.

All patients (9) with a mild motor deficit (MRC 4/5), who were treated surgically within $72 \mathrm{~h}$ after onset, recovered. However, only $64 \%$ of these patients treated after this time window regained full strength at 1 -year follow-up $(p=0.073$ ) (Fig. $3)$.

Analysis of sensory deficits did not reveal a significant impact of surgical timing.

Six patients $(5 \%)$ presented with a cauda equina syndrome with symptomatic vesicorectal dysfunction. Four patients (3.3\%) had experienced these symptoms for less than $24 \mathrm{~h}$ before admission and emergency discectomy. None of them showed any sequelae at 1-year follow-up. Unfortunately, two patients, who presented with vesicorectal dysfunction preexisting for more than 2 days and even a week, did not recover completely after decompression $(p=0.05)$.

Ninety-four patients $(78.3 \%)$ initially presented with any kind of sensory deficit. Forty-three patients $(44.8 \%)$ recovered from their sensory deficit 6 weeks after surgery, whereas 58 patients $(60.4 \%)$ recovered their sensory deficits after 1 year.

\section{Complications}

Complications occurred in 24 patients (20\%). The most common complication was a symptomatic reherniation, which was diagnosed based on clinical and radiologic findings in 14 cases $(11.7 \%)$. Of these, ten patients $(8.3 \%)$ underwent revision surgery within 1 year. The other four patients were successfully treated conservatively with complete recovery. An accidental durotomy occurred in 5 patients $(4.2 \%)$, none of them requiring revision surgery. Furthermore, two patients (1.7\%) did undergo fusion surgery for L5/S1 instability within 6 months after sequestrectomy. There was one revision for epidural hematoma and two patients $(1.7 \%)$ required drainage of a seroma. 
Table 3 Time-dependent recovery of $\mathrm{LDH}$ associated motor deficits

\begin{tabular}{lllll}
\hline $\begin{array}{l}\text { Duration of } \leq 3 / 5 \text { (MRC) } \\
\text { motor deficit }\end{array}$ & Incomplete recovery $(n)$ & Complete recovery after 1a $(n)$ & Total & $p^{*}$ \\
Paresis $\leq 72 \mathrm{~h}$ & 3 & 9 & 12 & \\
Paresis $>72 \mathrm{~h}$ & 13 & 0 & 13 & \\
Total & 16 & 9 & 25 & $<0.001$ \\
Duration of $4 / 5$ (MRC) & Incomplete recovery $(n)$ & Complete Recovery after 1a $(n)$ & Total & $p^{*}$ \\
$\quad$ motor deficit & 0 & 9 & 9 & \\
Paresis $\leq 72 \mathrm{~h}$ & 9 & 16 & 25 & \\
Paresis $>72 \mathrm{~h}$ & 9 & 25 & 34 & 0.073 \\
Total & & & & \\
\hline
\end{tabular}

\section{Discussion}

Our prospective study of 120 patients evaluating the impact of very early treatment, defined as surgical decompression of the affected nerve root within $72 \mathrm{~h}$ after symptom onset, showed significantly better outcome at 1-year follow-up in patients treated in an emergency manner. Patients suffering from a moderate to severe motor deficits (MRC $\leq 3$ ) highly benefit from very early discectomy as no one treated $72 \mathrm{~h}$ after onset regained full strength, whereas $75 \%$ decompressed within $72 \mathrm{~h}$ recovered completely. Also, there was a clear trend towards better outcome in patients with a mild motor deficit, if surgery was performed within $72 \mathrm{~h}$ after symptom onset. This is highly relevant in case of a symptomatic quadriceps palsy in order to prevent falls and further injuries, especially in active patients or people working in heights. However, these findings are controversial to previous publications including the official recommendations by the German Society of Neurology (DGN), which indicates surgery in case of moderate or severe paresis [10]. Petr et al. [20] defined surgery

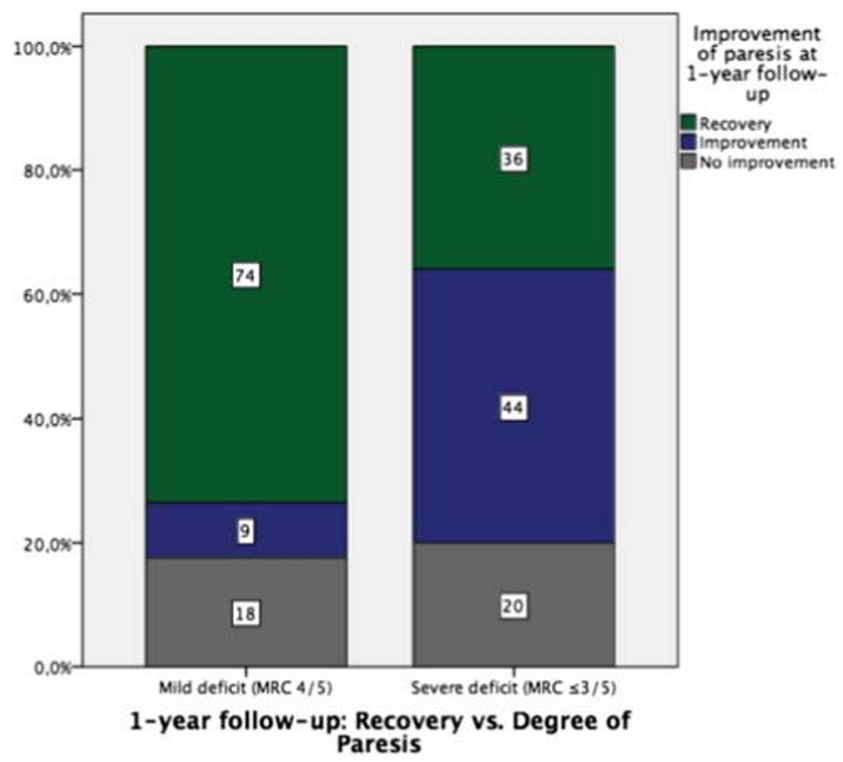

Fig. 1 Difference of recovery of mild vs. moderate and/or severe motor deficits irrespective of surgical timing within $48 \mathrm{~h}$ as early intervention, based on the recovery rate of cauda equina [20]. However, preliminary data of this study revealed incomplete recovery of moderate and/or severe paresis, if surgery was performed after a 72-h lapse of time.

In our study, $50 \%$ of all patients presented with a lumbar disc herniation and accompanying motor deficit. This distribution within the study population is in line with literature as motor function impairment due to a LDH is found in 40-82\% [19]. Of note, the series was initially enrolled to determine the need for an ACD; therefore, no conservatively treated control group exists. Due to intraoperative findings and implantation criteria, none of the patients with motor deficits received an ACD.

The majority of previous studies focused on whether to surgically treat persistent sciatica, but the role and timing of surgical intervention in case of motor deficits remained unclear. Superiority in short-term recovery of sciatica was shown for the surgical group [5, 28]. Yet, this early positive effect leveled out to a non-significant difference in the long term $[5,18,21,24]$.

Aono et al. [2] retrospectively demonstrated better outcome in early treated patients with a high degree paresis of ankle

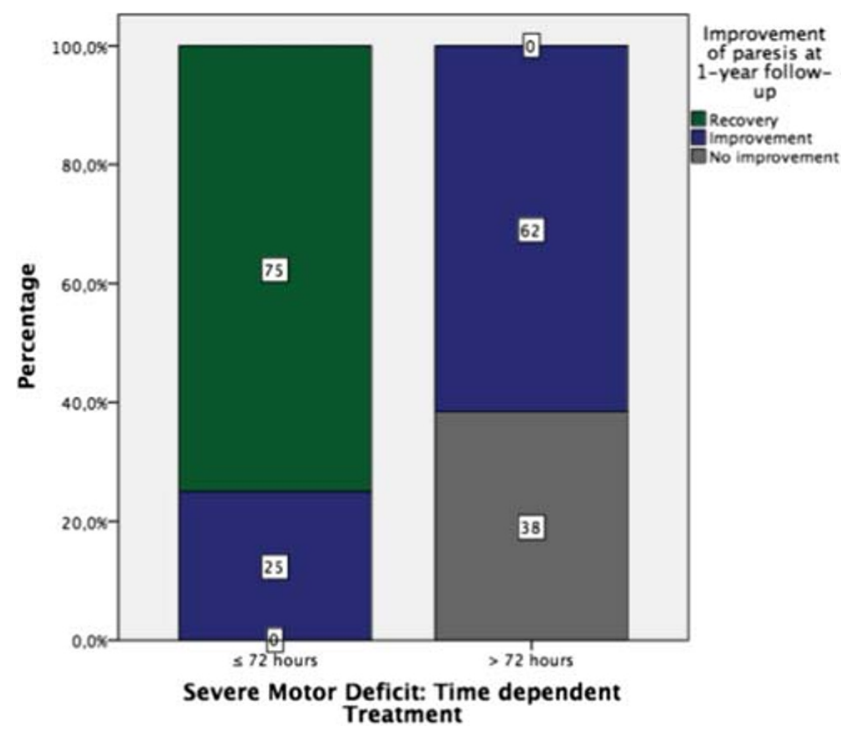

Fig. 2 Recovery of moderate and/or severe motor deficits $(M R C \leq 3 / 5)$ depending on surgical timing 


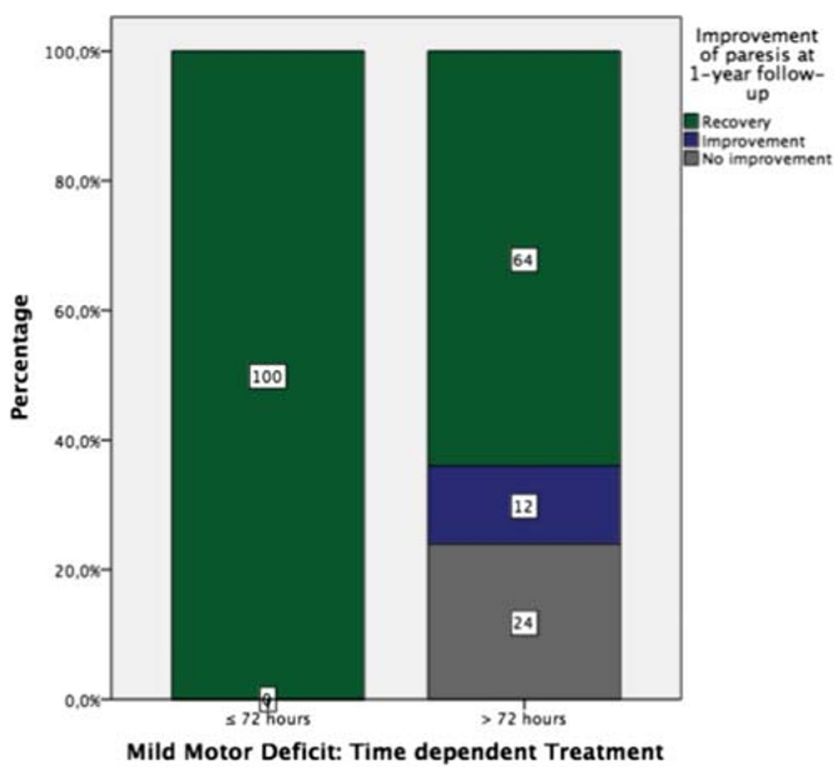

Fig. 3 Recovery of mild motor deficits (MRC 4/5) depending on surgical timing

dorsiflexion. However, the earliest time point of surgery was 4 days after onset and only 19\% reached an excellent result by regaining full strength [2]. An inverse relation between the degree of recovery of motor function and preoperative severity as well as symptom duration was described by Postacchini et al. [24]. The authors described an $84 \%$ recovery rate in patients with a mild and $61 \%$ rate in those with a severe motor deficit. No recovery was seen in patients undergoing surgery later than 3 months [24]. Lønne et al. [16] reported the degree of preoperative paresis as a significant risk factor as a severe paresis quadruplicated the risk of incomplete recovery. Timing was of peripheral importance, but surgery was performed late [16]. Dubourg et al. [7] compared the recovery rate between medically and surgically treated patients with a severe $(\leq 3 / 5 \mathrm{MRC})$ paresis. However, a longer course of sciatica, different types of herniation, and higher number of paretic muscles in the surgically treated group might have substantially limited the results. The authors reported no significant benefit in patients treated surgically with a motor deficit lasting for less than a month [7].

Recently, our group reported substantially better outcome in patients with severe motor deficits in a retrospective analysis if surgically treated within $48 \mathrm{~h} \mathrm{[20].}$

In this study, none of the affected muscles recovered completely, if nerve decompression was achieved after $72 \mathrm{~h}$ in patients with a severe paresis $(\mathrm{MRC} \leq 2 / 5)$, whereas all patients with mild motor deficits treated within $72 \mathrm{~h}$ made full motor function recovery.

Importantly, we identified the degree and duration of motor deficits to be a paramount predictor of residual deficits. While our findings regarding the sensory deficits are in line with the other recent studies [13, 27], the predictors for recovery of sensory deficits remain unclear. Notably, the sensory impairment does not seem to affect quality of life as much as persistent pain [13, 27].

In order to distinguish between a pain-induced erratic motor response and a neurologic motor deficit, analgesics were prescribed prior to reevaluation. In some cases, the patients' position and way of testing required modification.

The need for emergency surgical treatment has been reported in case of cauda equina syndrome [1, 4]. In our study, recovery of bladder and bowel dysfunction was achieved only in patients treated within the first $24 \mathrm{~h}$ after onset, which is in line with abovementioned studies $[1,4]$.

In summary, we are able to prospectively demonstrate the importance of early surgical intervention. This particular information can predict the likelihood of recovery and therefore should be used for patient management or triage.

The right indication and timing for surgery is pivotal to prevent persistent neurologic deficits and pain, as they potentially cause disability, substantially affecting the time to return to work and quality of life. Albeit short-term increased medical costs due to surgical treatment, operation, and hospital stay, surgical treatment is associated with lower overall costs [12].

\section{Limitations}

The surgical timing in case of motor deficits remains controversial, being affected by several factors. Of note, the exact time of onset is difficult to assess unless it significantly influences the patient's daily life and or mobility. Furthermore, the evaluation and degree of motor deficit varies across different centers, impeding comparison to other studies [19]. A limitation is the MRC scale as it is non-continuous. A grade of " 4 ," for example, encompasses a very large span of muscle weakness, ranging from minimal weakness to significant disability. This can be caused by pain provocation, poor compliance, or subjective clinical judgment $[8,17]$. This prospective study is missing a conservative control group, as it focused on the time-dependent outcome of LDH-associated sensorimotor deficits. In spite of a small number, this study clearly indicates superior motor function recovery, if surgery is being performed within a 72 -h period.

\section{Conclusions}

Early surgical treatment must be advised in case of severe motor deficits and/or cauda equina syndrome to allow complete and fast recovery. We identified the degree and duration of motor deficits to be a paramount predictor of residual deficits. In particular, patients with short-lived moderate and severe motor deficits should undergo surgery within $72 \mathrm{~h}$ after onset. Even in patients with a mild weakness, early surgical intervention showed a clear trend towards better outcome, which can be highly relevant depending on the disability resulting from the deficit. 
Funding Open access funding provided by University of Innsbruck and Medical University of Innsbruck. The study conduction was supported by Intrinsic Therapeutics. The senior author has received speaker and consultant honoraria by Intrinsic Therapeutics.

\section{Compliance with ethical standards}

All procedures performed in studies involving human participants were in accordance with the ethical standards of the institutional and/or national research committee and with the 1964 Helsinki declaration and its later amendments or comparable ethical standards.

Informed consent was obtained from all individual participants included in the study.

Conflict of interest The authors declare that they have no conflict of interest.

Open Access This article is licensed under a Creative Commons Attribution 4.0 International License, which permits use, sharing, adaptation, distribution and reproduction in any medium or format, as long as you give appropriate credit to the original author(s) and the source, provide a link to the Creative Commons licence, and indicate if changes were made. The images or other third party material in this article are included in the article's Creative Commons licence, unless indicated otherwise in a credit line to the material. If material is not included in the article's Creative Commons licence and your intended use is not permitted by statutory regulation or exceeds the permitted use, you will need to obtain permission directly from the copyright holder. To view a copy of this licence, visit http://creativecommons.org/licenses/by/4.0/.

\section{References}

1. Ahn UM, Ahn NU, Buchowski JM, Garrett ES, Sieber AN, Kostuik JP (2000) Cauda equina syndrome secondary to lumbar disc herniation: a meta-analysis of surgical outcomes. Spine (Phila Pa 1976) 25(12):1515-1522

2. Aono H, Iwasaki M, Ohwada T, Okuda S, Hosono N, Fuji T, Yoshikawa H (2007) Surgical outcome of drop foot caused by degenerative lumbar diseases. Spine (Phila Pa 1976). https://doi. org/10.1097/01.brs.0000259922.82413.72

3. Arts MP, Peul WC, Leiden-Hague Spine Intervention Prognostic Study Group L- THSIPSG (2011) Timing and minimal access surgery for sciatica: a summary of two randomized trials. Acta Neurochir (Wien) 153(5):967-974

4. Bednar DA (2016) Cauda equina syndrome from lumbar disc herniation. CMAJ 188(4):284

5. Buttermann GR (2004) Treatment of lumbar disc herniation: epidural steroid injection compared with discectomy: a prospective, randomized study. J Bone Jt Surg - Ser A 86(4):670-679

6. Davis D, Vasudevan A (2018) Sciatica. StatPearls Publishing

7. Dubourg G, Rozenberg S, Fautrel B et al (2002) A pilot study on the recovery from paresis after lumbar disc herniation. Spine (Phila Pa 1976) 27(13):1426-1431

8. Escolar DM, Henricson EK, Mayhew J, Florence J, Leshner R, Patel KM, Clemens PR (2001) Clinical evaluator reliability for quantitative and manual muscle testing measures of strength in children. Muscle Nerve 24(6):787-793

9. Frymoyer JW (1988) Back Pain and Sciatica. N Engl J Med 318(5): 291-300

10. Glocker FX (2018) Leitlinien für Diagnostik und Therapie in der Neurologie - Lumbale Radikulopathie

11. Gugliotta M, da Costa BR, Dabis E, Theiler R, Jüni P, Reichenbach S, Landolt H, Hasler P (2016) Surgical versus conservative treatment for lumbar disc herniation: a prospective cohort study. BMJ Open 6(12):e012938

12. Hansson E, Hansson T (2007) The cost-utility of lumbar disc herniation surgery. Eur Spine J 16(3):329-337

13. Ivanic GM, Pink TP, Homann NC, Scheitza W, Goyal S (2001) The post-discectomy syndrome. Arch Orthop Trauma Surg 121(9):494-500

14. Konstantinou K, Dunn KM (2008) Sciatica: review of epidemiological studies and prevalence estimates. Spine (Phila Pa 1976) 33(22):2464-2472

15. Lagerbäck T, Fritzell P, Hägg O et al (2019) Effectiveness of surgery for sciatica with disc herniation is not substantially affected by differences in surgical incidences among three countries: results from the Danish, Swedish and Norwegian spine registries. Eur Spine J 28(11):2562-2571

16. Lønne G, Solberg TK, Sjaavik K, Nygaard ØP (2012) Recovery of muscle strength after microdiscectomy for lumbar disc herniation: a prospective cohort study with 1-year follow-up. Eur Spine J. https:// doi.org/10.1007/s00586-011-2122-x

17. O'Neill S, Jaszczak SLT, Steffensen AKS, Debrabant B (2017) Using $4+$ to grade near-normal muscle strength does not improve agreement. Chiropr Man Ther. https://doi.org/10.1186/s12998-017-0159-6

18. Österman H, Seitsalo S, Karppinen J, Malmivaara A (2006) Effectiveness of microdiscectomy for lumbar disc herniation. Spine (Phila Pa 1976) 31(21):2409-2414

19. Overdevest GM, Vleggeert-Lankamp CLAM, Jacobs WCH, Brand R, Koes BW, Peul WC (2014) Recovery of motor deficit accompanying sciatica - subgroup analysis of a randomized controlled trial. Spine J 14(9):1817-1824

20. Petr O, Glodny B, Brawanski K, Kerschbaumer J, Freyschlag C, Pinggera D, Rehwald R, Hartmann S, Ortler M, Thomé C (2019) Immediate versus delayed surgical treatment of lumbar disc herniation for acute motor deficits. Spine (Phila Pa 1976) 44(7):454-463

21. Peul WC, van Houwelingen HC, van den Hout WB, Brand R, JAH E, Tans JTJ, Thomeer RTWM, Koes BW, Leiden-The Hague Spine Intervention Prognostic Study Group (2007) Surgery versus prolonged conservative treatment for sciatica. N Engl J Med 356(22):2245-2256

22. Peul WC, van den Hout WB, Brand R, Thomeer RTWM, Koes BW, Leiden-The Hague Spine Intervention Prognostic Study Group (2008) Prolonged conservative care versus early surgery in patients with sciatica caused by lumbar disc herniation: two year results of a randomised controlled trial. BMJ 336(7657):1355-1358

23. Peul WC, Arts MP, Brand R, Koes BW (2009) Timing of surgery for sciatica: subgroup analysis alongside a randomized trial. Eur Spine J 18(4):538-545

24. Postacchini F, Giannicola G, Cinotti G (2002) Recovery of motor deficits after microdiscectomy for lumbar disc herniation. J Bone Jt Surg 84(7):1040-1045

25. Sharma H, Lee SWJ, Cole AA (2012) The management of weakness caused by lumbar and lumbosacral nerve root compression. $\mathrm{J}$ Bone Joint Surg Br 94-B(11):1442-1447

26. Thomé C, Klassen PD, Bouma GJ et al (2018) Annular closure in lumbar microdiscectomy for prevention of reherniation: a randomized clinical trial. Spine J. https://doi.org/10.1016/j.spinee.2018.05.003

27. Tschugg A, Lener S, Hartmann S, Neururer S, Wildauer M, Thomé C, Löscher WN (2016) Improvement of sensory function after sequestrectomy for lumbar disc herniation: a prospective clinical study using quantitative sensory testing. Eur Spine J 25(11):3543-3549

28. Weinstein JN, Lurie JD, Tosteson TD, Tosteson ANA, Blood EA, Abdu WA, Herkowitz H, Hilibrand A, Albert T, Fischgrund J (2008) Surgical versus nonoperative treatment for lumbar disc herniation: four-year results for the Spine Patient Outcomes Research Trial (SPORT). Spine (Phila Pa 1976) 33(25):2789-2800

Publisher's note Springer Nature remains neutral with regard to jurisdictional claims in published maps and institutional affiliations. 